\title{
Twenty years of PLM - The Good, the Bad and the Ugly
}

\author{
${ }^{1}$ HSR, Rapperswil, Switzerland \\ urs.meier@hsr.ch \\ ²lorian.fischli@hsr.ch \\ 3 anita.sohrweide@hsr.ch \\ ${ }^{4}$ felix.nyffenegger@hsr.ch
}

Urs Meier $^{1}$, Florian Fischli ${ }^{2}$, Anita Sohrweide ${ }^{3}$, Felix Nyffenegger ${ }^{4}$,

\begin{abstract}
Looking back at the past 20 years of experience in implementation and customization of PLM applications, it can be observed that the technological complexity of the systems has increased dramatically, but it does not match the growing complexity of the business. These observations are discussed in research as well as in the PLM blogger community.

Vendors implement the new technologies primarily on the upper application levels, which produces on one side applications with the latest technology, that represent the latest research trends. On the other hand, on the lower levels of the architectures often use the same (old) technologies. The increasing number of integrated capabilities creates more diverse PLM-systems. And thus, creates a broader customer base. However, this brings the individual company and existing customers only a limited benefit. In contrast, systems increase in complexity, which is barely manageable - from the vendors and especially from the customer's perspective. The result is little added value and at the high price of lost flexibility.

This increase in system complexity, does not coincide with the increase of complexity of enterprises, which is mainly driven by growing organizational complexity (collaboration, decentralization) and increasing product complexity. Industrial companies require a deeper and better support of their existing processes and greater flexibility in adapting the tools to a changing business environment.

These findings result from a structured review of more than 30 PLM projects in various industries, from SME's to globally active large companies, 6 primary cases will be presented in this article.
\end{abstract}

Keywords: PLM, case study mapping, project experience, trends, organizational change, tool complexity

\section{$1 \quad$ Introduction}

New topics such as Industry 4.0, closed loop PLM, digital twins, and others are discussed in research and strongly promoted by PLM vendors. Also, PLM vendors 
have invested into better flexibility and scalability and certainly moved from the toolbox approach to more out of the box functionality.

However, based on our experience, the scope of use cases in PLM implementations has not changed much during the past two decades. Yet, PLM Projects get more complex, time to production becomes longer, and the need for IT infrastructure has increased drastically.

This seems to be surprising and could lead to the conclusion, that either vendors do not meet the customer needs, or as some vendors say: the customers are ten years behind the tools. At least, this observation or sensation lead us, to have a closer look at the development of PLM during the past two decades.

In contrast to other studies, that analyze the elapsed development of PLM by literature reviews [1], knowledge from research experts [2] or quantitative analysis of literature [3], [4], the aim of this study is to share our personal experience (consultants and researchers). With a set of case studies, we created a structured look back on PLM projects we know in depth: what was the nature of the customer and its product, what was the scope in terms of processes and organizations, which tools and technologies were involved and how well the targets were achieved.

\section{Related research}

Scientific work. Various authors discuss the history and future trends in PLM. Terzi et Al. set a reference about the state of PLM for the research community in many ways [2]. It gives a detailed review of experts to PLM history and their vision for the future steps of the PLM in terms of emerging issues and topics that industrial practitioners and researchers need to address. Among others the concepts of closed loop lifecycle management and a new role of PLM in the age of digitization are discussed.

Bhatt et Al. [4] as well as Nyffenegger et Al. present large scale bibliometric studies of scientific literature in PLM. From their work, it can be concluded, that new topics such as BIM (building information modelling) or IoT (internet of things) are emerging. However, the later study also shows that the major topics mentioned by author keywords remain the same over the past 10 years [3].

Abramovici summarizes the current PLM state of the art and describes the main expected development directions in PLM and shows some results from PLM research projects in [5]. He sees the future of PLM in better integration of multidisciplinary products and special attention on "smart products" with embedded information devices on board. Each device will have a unique identification and will track and trace its own lifecycle. In this context, PLM will gain on importance in the next decade. However, missing industry standards and the complexity of current PLM solutions could be the bottleneck in this process.

PLM web community. In addition to scientific publications, there is also an active blogger community discussing the state of PLM. These discussions reflect a more subjective or even opinionated view, based on the personal expertise of the authors. 
However, longtime experience of these authors leads to a very differentiated view on current development in PLM.

Madjar mentions the cyclic trends in PLM, and asks if PLM is recycling itself [6]. During the last 20 years, he observes oscillating opinions about several topics such as customization or not, maintaining silos in best-in-bread systems vs. all-encompassing systems, cloud approach vs. on premise, model-based engineering, single BoM vs. multiple BoMs etc. As an example, there are times where customization is a bad word, while in other times it is natural way of improving efficiency.

In response, Shilovitsky compares in [7] the development of PLM technologies to startups. The success of new concepts depends on the right timing. Technologies or concepts (e.g. web base PLM) have been appearing in the past and dying again. 10 years later such a technology might suddenly be very attractive. Users and technology are ready. He sees cyclic behavior not as recycling, but rather as a necessity to choose the right time.

Complementary, he argued earlier, that old PLM ideas in people's minds are hard to escape [8]. Similar, also the limits of existing PLM architectures are hard to break. Most of them are 15 to 20 years old and completely server and database centric [9]. This does not fit the need for modern engineering and manufacturing environments, which are more likely a network of resources (see also, the "cobbler" model, mentioned in [2]). In some cases, PLM needs new inspiration to unlock future thinking.

One strategy to break out of these existing best practices is currently intensely discussed in industry as well as in research: the "bimodal" approach [10]. Adapting an established system and all its data and processes to a novel concept might involve a lot of work, resistance and risk. It is likely that this will result in a compromise between the old and the new concept. Instead, the bimodal approach suggests exploring new unpredictable concepts in a separate system without barriers (mode 2), while the existing system is optimized for the predictable and well-understood concepts (mode 1). Marrying a more predictable evolution of products and technologies (Mode 1) with the new and innovative (Mode 2) is the essence of an enterprise bimodal capability [11].

While these interesting inputs from PLM bloggers contribute on a substantial but personal level to the understanding of PLM, researcher do not widely share personal experience of implementation projects. None of them presents data to the history and the experience of real PLM implementations, and how these changed over time. We are aware that the selection of the samples is biased be the location and expertise of the authors. Still, we believe, this detailed, but subjective view on the history of PLM adds a new complementary perspective to the work described above.

\section{$3 \quad$ Methodology}

This study is a mapping of case studies into a standardized schema, to allow comparison and detection of trends along these cases. All case studies are based on consulting interventions executed by one or several of the authors. This ensures deep insight into these PLM projects, but of course the interpretation is a subject of indi- 
vidual judgment by the authors. However, the step of abstraction (mapping) allows an unbiased, or less biased, discussion of the evolution of PLM projects along the dimensions proposed. In addition, all cases which are selected for presentation in this publication are reviewed with the company to assure correctness of the data, particularly the timeline.

The interventions are characterized by different types of companies, different product types, and also by very different size of project scope. So, these factors must be respected in the interpretation of the case studies. Also, based on previous research and comments from bloggers, we were curious on how these PLM scenarios developed over time. The history of technology (servers, clients, upgrades, new tools, etc.) on one hand and the development of organizations on the other hand need to be understood. Therefore, the dimensions shown in Table 2 were chosen for the mapping.

Table 1 - Dimensions of the case study mapping

\begin{tabular}{|c|c|}
\hline Dimension & Description \\
\hline Company Name & Not shown in publication \\
\hline Company size & $\begin{array}{l}\text { Classification of the size into the following categories } \\
\text { of total employees. Based on the classification sug- } \\
\text { gested by the European Commission [12]. } \\
1:<50 \\
2:<250 \\
3:>250\end{array}$ \\
\hline Company domain & $\begin{array}{l}\text { A rough categorization of the company domain, such } \\
\text { as Plant-Engineering, Automotive or Building Tech- } \\
\text { nologies. }\end{array}$ \\
\hline Organization complexity & $\begin{array}{l}\text { How complex the company was at the time of the } \\
\text { intervention. } \\
\text { 1: Local development and local manufacturing } \\
\text { 2: Local development and global manufacturing } \\
\text { 3: Global development and global manufacturing }\end{array}$ \\
\hline Product complexity & $\begin{array}{l}\text { To characterize the nature of the product complexity } \\
\text { we decided to classify them by the product strategy or } \\
\text { (strategy to connect sales with production). Since } \\
\text { these strategies clearly influence the setup of PLM } \\
\text { concepts. } \\
\text { 1: MTS (Make to Stock) } \\
\text { 2: ATO (Assemble to Order) } \\
\text { 3: MTO (Make to Order) } \\
\text { 4: ETO (Engineer to Order) }\end{array}$ \\
\hline PLM tool & Not shown in publication \\
\hline Main PLM capabilities & $\begin{array}{l}\text { The most important use cases and functionalities that } \\
\text { were implemented to achieve the customer's targets. }\end{array}$ \\
\hline Processes involved & $\begin{array}{l}\text { The business processes that were primarily targeted by } \\
\text { the project. }\end{array}$ \\
\hline
\end{tabular}




\begin{tabular}{|l|l|}
\hline Organizations involved & $\begin{array}{l}\text { The organizational units that contributed to achieve } \\
\text { the projects targets. These do not necessarily match } \\
\text { with the processes. E.g. the service organization might } \\
\text { be involved to add service relevant master data as part } \\
\text { of the product development process. }\end{array}$ \\
\hline Year & $\begin{array}{l}\text { Year, when the intervention of the authors started. The } \\
\text { start of the PLM campaign might be earlier. }\end{array}$ \\
\hline Target history & $\begin{array}{l}\text { The major targets of the company along the timeline } \\
\text { of implementation }\end{array}$ \\
\hline $\begin{array}{l}\text { Timeline hardware re- } \\
\text { quirements (server) }\end{array}$ & $\begin{array}{l}\text { Simultaneous use of Server of the company for daily } \\
\text { work, maintenance and updating. }\end{array}$ \\
\hline $\begin{array}{l}\text { Timeline hardware cli- } \\
\text { ents }\end{array}$ & $\begin{array}{l}\text { Number of users and working stations for PLM inter- } \\
\text { action as CAD-station (engineering), office-station } \\
\text { (light) etc. }\end{array}$ \\
\hline
\end{tabular}

As mentioned in Table 1, the name of the company and the vendor of the PLM tool will not be published, these are not considered relevant to the interpretation of the data and would probably cause damage to the involved actor. Furthermore, it is important to better understand the values of PLM capabilities. These were as far as possible aligned with the keywords preferably chosen by other authors [3], but bundled into clusters which are explained in Table 2 .

Table 2 - Values of PLM capabilities

\begin{tabular}{|l|l|}
\hline PLM Capability & Description \\
\hline Engineering change management & $\begin{array}{l}\text { Release workflows, ECR/ECO/ECN pro- } \\
\text { cesses, business rules. }\end{array}$ \\
\hline MCAD integration & $\begin{array}{l}\text { MCAD integration, configuration manage- } \\
\text { ment for MCAD. }\end{array}$ \\
\hline ECAD integration & $\begin{array}{l}\text { ECAD integration, configuration manage- } \\
\text { ment for ECAD. }\end{array}$ \\
\hline Global collaboration & $\begin{array}{l}\text { Replication, access rights and roles, concur- } \\
\text { rent engineering. }\end{array}$ \\
\hline Item and BOM management & $\begin{array}{l}\text { Item centric principle, BOM management, } \\
\text { BOM views, lifecycle status, configuration } \\
\text { management, effectivities. }\end{array}$ \\
\hline Variant management & $\begin{array}{l}\text { Overloaded BOMs including variants and } \\
\text { options, configuration master data. }\end{array}$ \\
\hline Description catalogue & $\begin{array}{l}\text { Standard terminology and schemas for texts } \\
\text { such as names or descriptions. }\end{array}$ \\
\hline Mechatronics & $\begin{array}{l}\text { Mechatronics structures and/or Software } \\
\text { Integration. }\end{array}$ \\
\hline Requirements management & $\begin{array}{l}\text { Management of requirements and/or func- } \\
\text { tional structures in the PLM system, re- } \\
\text { quirement tractability. }\end{array}$ \\
\hline
\end{tabular}




\begin{tabular}{|l|l|}
\hline ERP interface & $\begin{array}{l}\text { Interface between PLM and ERP system, } \\
\text { e.g. item, BOM, lifecycle status, etc. }\end{array}$ \\
\hline Master data for service & $\begin{array}{l}\text { Service relevant master data such as spare } \\
\text { parts, spare part kits etc. and durability in- } \\
\text { formation, automatic generation of spare } \\
\text { parts catalogs. }\end{array}$ \\
\hline Classification & $\begin{array}{l}\text { Classifications of items for better manage- } \\
\text { ment of items. }\end{array}$ \\
\hline Phase-out process & System supported phase-out process \\
\hline Information and productivity apps & $\begin{array}{l}\text { Application for easy and fast information } \\
\text { access to PLM or ERP information (e.g. } \\
\text { item information, paperless production, etc.) }\end{array}$ \\
\hline
\end{tabular}

\section{Case Studies}

A total of 39 case studies were considered. Since it is not possible to list all cases in this publication, a set of representative samples was selected to be presented in detail in Table 3 of the appendix. The samples were chosen to show the typical variety of organizations and product strategies. Also, they give an idea of the typical steps in the timeline of PLM development. The table shows the evolution of PLM targets as well as the infrastructure used for different stages of the individual PLM journeys. A more detailed explanation of the listed PLM capabilities can be found in Table 1 .

From the case studies the following observations can be captured:

i. Looking at all 39 case studies, the scope of PLM stays within the range of traditional targets (as listed in Table 1). Only few exceptions look at more advanced topics such as mechatronic simulation or test management.

ii. Typically, the steps of maturity include: first focus on MCAD integration and item and BOM management, next focus ERP integration and full engineering change management process and mechatronics structures, then optimization and minor enhancements, finally providing user specific information through app-like concepts.

iii. Companies that face a change organizational complexity (focus on global collaboration) tend to slow down PLM activities (case 1,2,3,5).

iv. Companies with constant organizations are able to keep constant pace in improvement (case 4, partially 6).

v. Changes or upgrades of the PLM tool and/or CAD tool cause an interruption of several years (case 1,2,3,5).

vi. Scenarios with global collaboration tend to ask for remarkably more IT infrastructure (case 2, 5). Only one case achieved a reduction of IT complexity through global consolidation (case 3).

vii. Upgrades or replacement of legacy system almost all cases lead to more complex IT infrastructure $(1,2,3,5)$.

viii. Some small companies do not have a need to increase the scope of PLM (case 6). 


\section{Discussion}

Observing these mapped case studies, the following hypothesis can be formulated.

Hypothesis I. PLM systems become more and more inflated and less flexible. This is the result of a continuous expansion of PLM capabilities by integrating a large number of sub-systems into current PLM platforms. This effect was increased by the acquisition strategy of PLM vendors to gain market share.

PLM Acquisitions of new technologies or competitors often follow the merging of the purchased tool landscape with the own architecture. This leads by nature to increase in complexity of the tool, but not to a quantifiable benefit to support of the needs of the end-user. For example, the growing number of available $3^{\text {rd }}$ party tools integrations increase the number of potential customers for the system supplier, but often only creates limited added value for the existing clientele. In contrast, this leads to an ugly effect: System upgrades result in large scale projects, that might throw a company back for years instead of continuously developing their PLM maturity (observation v., vii.). Some companies don't even have a need to increase their PLM scope and are still forced to keep pace with the technology (observation viii.).

Another driver for the increasing complexity is the shift of technology from e.g. fat clients to web clients or apps, or as recently discuss form centralized databases to distributed organization of data. Such shifts in paradigm or new technologies are typically addressed by adding a new layer to the existing software architecture. The underlying basic functionality has not really much changed. At least, it is questionable if this vast mixture of technologies really supports the intention of the original paradigm.

Hypothesis II. Not just the PLM tools, also many companies have increased remarkably in complexity. The need for global collaboration and flexibility of PLM systems to continuously changing organizations is growing (observation iii., iv., vi.).

While ten years ago, the scope of many SMEs was to support the engineering team in the head quarter, recent company structures require true global engineering collaboration. Acquisition and merging has played an important role in the strategy of many enterprises (SMEs and large companies, observation iii.). Ten years ago, the focus was mostly on integration of mechanical CAD. Today it has shifted to the central platform for mechanic, electronic and software development (observation ii.). This trend might correlate in first place with the increasing complexity of the products. As a further driver for growing complexity, the growing decentralization can also be viewed. More and more companies have outsourced parts of their development sites to other countries.

Conclusion. While companies are rolling the same themes (observation i., [5], [6]) in increasingly complex and globally organized environments, the tools focused on the integration of more and more capabilities to grow market coverage . The suppliers and the companies have not developed in the same direction. Hence, the statement 
"customers are 10 years behind the tools" is not a surprise. They simply have another focus.

From hypothesis, II it can be concluded that it would be important for companies to solve their core problems (e.g. collaboration) efficiently and, above all, scalable and flexible towards changing organization, product strategies and business models. Then the willingness would certainly exist, to approach the next steps in the PLM maturity degree. However, based on hypothesis I, established PLM manufacturers might have a hard time to achieve this demand [8]. They aim of tools to cover more and more functionality was done on the price of flexibility (and sometimes usability).

A real exemption for the reduction of system complexity and the increase of flexibility would probably only succeed on the greenfield. This, of course, requires a lot of courage. Companies and consultants currently react to this dilemma with the bi-modal approach [10]. Eventually, it would not be surprising if a new disruptive PLM technology managed to shake the PLM world during the next decade. 


\section{Appendix}

\begin{tabular}{|c|c|c|c|c|c|c|c|c|c|c|c|}
\hline $\begin{array}{l}\text { Case } \\
\text { No. }\end{array}$ & Size & Company Domain & \begin{tabular}{|c|}
$\begin{array}{c}\text { organization } \\
\text { complexity }\end{array}$ \\
\end{tabular} & \begin{tabular}{|c|} 
Product \\
complexity
\end{tabular} & Main PLM capabilities & Processes involved & Organizations involved & Year & Target history & $\begin{array}{l}\text { Timeline hardware } \\
\text { requirements (server) }\end{array}$ & \begin{tabular}{|l} 
Timeline hardware \\
clients
\end{tabular} \\
\hline 1 & 3 & Machine building & 3 & 3 & $\begin{array}{l}\text { - Engineering change management } \\
\text { - MCAD/ECAD integration } \\
\text { - ERP interface } \\
\text { - BOM management } \\
\text { - Variant management } \\
\text { - Masterdata for service (electronic spare } \\
\text { parts catalog, } 6 \text { languages) }\end{array}$ & $\begin{array}{l}\text { - Product development } \\
\text { - Product documentation } \\
\text { (Spare parts cataloge) } \\
\text { - Service (Spare parts) }\end{array}$ & \begin{tabular}{|l|} 
- Mechanical and \\
electrical engineering \\
- Documentation \\
- Service
\end{tabular} & 1998 & $\begin{array}{l}\text {-1998: PLM evaluation } \\
\text { - 1999: PLM implementation } \\
\text { - 1999: PLM re-evaluation } \\
\text { (because of PLM supplier merge / end of SW) } \\
\text { - 1999/2000: PLM re-implementation } \\
\text {-2000: Data migration } \\
\text { - 2000-2006: Several enhancements } \\
\text {-2006-2016 Operation/selective enhancements } \\
\text { - 2016: Re-Work/upgrade ERP-interface } \\
\text { - 2016-today: Operation/selective enhancements }\end{array}$ & $\begin{array}{c}-1998-\text { today: } 1 \times \text { server (PROD) } \\
1 \times \text { server (TEST) }\end{array}$ & 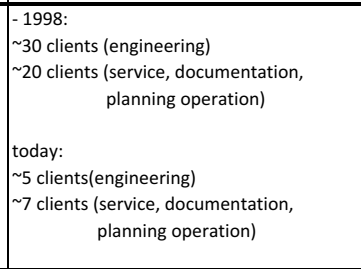 \\
\hline 2 & 3 & Aerospace & 3 & 4 & $\begin{array}{l}\text { - Engineering change management } \\
\text { - MCAD (Multi-CAD) integration } \\
\text { - BOM management } \\
\text { - Global collaboration } \\
\text { - Regulation conformity }\end{array}$ & $\begin{array}{l}\text { - Product development } \\
\text { - Product structuring } \\
\text { - Purchase }\end{array}$ & $\begin{array}{l}\text { - Mechanical and } \\
\text { electrical engineering } \\
\text { - Config control }\end{array}$ & 2013 & $\begin{array}{l}\text {-2013: PLM implementation } \\
\text {-2014/2015: Selective enhancements } \\
\text { - 2016/2017: PLM-SW upgrade } \\
\text { - 2017: Selective enhancements } \\
\text { - 2018: ERP integration }\end{array}$ & $\begin{array}{r}-2013-2016: 2 \times \text { server (PROD) } \\
\text { 2x server (TEST) } \\
-2017-: \text { 10x server (PROD) } \\
2 x \text { server (TEST) }\end{array}$ & 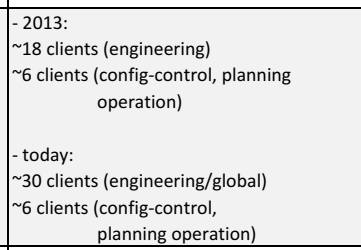 \\
\hline 3 & 3 & Plant-Engineering & 3 & $2,3,4$ & $\begin{array}{l}\text { - Engineering change management } \\
\text { - MCAD integration } \\
\text { - Global collaboration } \\
\text { - BOM management } \\
\text { - Variant management } \\
\text { - Description catalogue } \\
\text { - Global manufacturing masterdata } \\
\text { (7 languages) } \\
\text { - Classification (standardization) } \\
\text { - Masterdata for service } \\
\text { - ERP interface }\end{array}$ & $\begin{array}{l}\text { - Product development } \\
\text { for plant components }\end{array}$ & \begin{tabular}{|l|} 
- Mechnical engineering \\
- Manufacturing \\
- Standardization \\
- Service
\end{tabular} & 1998 & $\begin{array}{l}\text { - until 1999: Legacy PDM tool } \\
\text { - 1999: Introduction of new PLM (due to CAD strategy). } \\
\text { Individual systemes per site. } \\
\text {-2003: Attempt for global PLM } \\
\text { (failure, due to poor acceptance) } \\
\text {-2010: Change of CAD system } \\
\text {-2010: Unifying PLM functionality: } \\
\text { same configuration for all sites } \\
\text {-2011: Re-thinking the scope of PLM } \\
\text { (because of PLM supplier merge / end of SW) } \\
\text {-2011: Evaluation of global PLM plattform } \\
\text {-2012: Implementation and migration } \\
\text { global PLM plattform (full capabilities) } \\
\text {-2013: Pilot with one BU and } 2 \text { sites } \\
\text { - 2014-today: Global rollout (6 BUs, } 14 \text { Sites) } \\
\end{array}$ & $\begin{array}{l}- \text { HW legacy PLM systems } \\
\text { - PROD: } 24 \text { server (4 per site) } \\
\text { - TEST: } 4 \text { server } \\
\text { - Hardware global PLM plattform } \\
\text { - PROD: } 6 \text { server } \\
\text { (application server) } \\
10 \text { (vault replication) }\end{array}$ & \begin{tabular}{|l}
$-2010:$ \\
- 200 (engineering) \\
$\sim 600$ (light) clients (total of all engineering \\
$\quad$ sites, in seperate PLM systems) \\
-today: \\
$\sim 550$ (engineering) \\
$\sim 1000$ (light clients)
\end{tabular} \\
\hline
\end{tabular}

Table 3-1- Mapped case studies 


\begin{tabular}{|c|c|c|c|c|c|c|c|c|c|c|c|}
\hline $\begin{array}{l}\text { Case } \\
\text { No. }\end{array}$ & Size & Company Domain & \begin{tabular}{|c|}
$\begin{array}{c}\text { Organization } \\
\text { complexity }\end{array}$ \\
\end{tabular} & \begin{tabular}{|c|} 
Product \\
complexity
\end{tabular} & Main PLM capabilities & Processes involved & Organizations involved & Year & Target history & $\begin{array}{l}\text { Timeline hardware } \\
\text { requirements (server) }\end{array}$ & $\begin{array}{l}\text { Timeline hardware } \\
\text { clients }\end{array}$ \\
\hline 4 & 2 & Subsystem supplier & 1 & 2,3 & $\begin{array}{l}\text { - Engineering change management } \\
\text { - MCAD/ECAD integration } \\
\text { - BOM management } \\
\text { - ERP interface }\end{array}$ & \begin{tabular}{|l|} 
- Product development \\
- Product structuring
\end{tabular} & $\begin{array}{l}\text { Mechanical and } \\
\text { electrical Engineering } \\
\text { - Manufacturing }\end{array}$ & 2011 & $\begin{array}{l}\text {-2009: Initiation of discussion about PLM } \\
\text { (managing technical documents) } \\
\text { - 2011: PLM evaluation } \\
\text { - 2012: PLM implementation (full capabilities) } \\
\text { - 2013: Engineering change management } \\
\text { - 2014: ECAD Integration } \\
\text { - 2015: Minor enhancements } \\
\text { - 2017: Upgrade project }\end{array}$ & $\begin{array}{c}\text {-2011-today: } 1 \times \text { server (PROD) } \\
\text { 1x server (TEST) }\end{array}$ & \begin{tabular}{|l|}
-2011-today: \\
\%30 clients (engineering) \\
20 clients (only document management)
\end{tabular} \\
\hline 5 & 2 & \begin{tabular}{|l|}
$\begin{array}{l}\text { Electronic component } \\
\text { supplier }\end{array}$ \\
\end{tabular} & $\begin{array}{l}-1999: 1 \\
>2009: 3\end{array}$ & 1 & $\begin{array}{l}\text {-Engineering change management } \\
\text { - MCAD/ECAD integration } \\
\text { - BOM management } \\
\text { - Global collaboration (advanced access } \\
\text { rights) } \\
\text { - Classification } \\
\text { - ERP interface } \\
\text { - Phase-Out process } \\
\text { - Item information app }\end{array}$ & - Product development & \begin{tabular}{|l|} 
- Mechanical \\
electrical Engineering \\
- Manufacturing
\end{tabular} & 1996 & 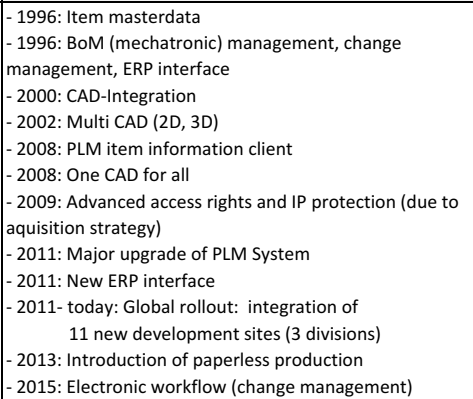 & $\begin{array}{l}\text { - 1996-2011 1x server (PROD) } \\
\text { - 2010: Virtualization } \\
\text { - 2011: 2x server (PROD) + 4x } \\
\text { DFM (replication), 2x server } \\
\text { (TEST) } \\
\text { - 2016: 3x server (PROD) 2x } \\
\text { DFM (replication), 3x server } \\
\text { (TEST), }\end{array}$ & $\begin{array}{l}\text {-until 2010: } 60 \text { clients (engineering) } \\
\text {-today: } \\
90 \text { clients (engineering) } \\
40 \text { additional clients (documemnt, item) }\end{array}$ \\
\hline 6 & 2 & $\begin{array}{l}\text { Component and } \\
\text { mechanical system } \\
\text { supplier }\end{array}$ & $\begin{array}{l}<2005: 1 \\
>2005: 3\end{array}$ & 1,2 & $\begin{array}{l}\text { - Engineering change management } \\
\text { - MCAD integration } \\
\text { - BOM management }\end{array}$ & $\begin{array}{l}\text { - Product development } \\
\text { - Equipment development }\end{array}$ & \begin{tabular}{|l} 
- Mechanical \\
engineering \\
- Equipment \\
engineering
\end{tabular} & 2005 & $\begin{array}{l}\text {-2004: MCAD with PDM integration } \\
\text { - 2004: MCAD change } \\
\text { - 2005: PDM integration for new MCAD }\end{array}$ & $1 \times$ server (PROD) & $\begin{array}{l}\text {-2004: 10 clients (engineering) } \\
-2005: ~ \sim 14 \text { clients (engineering) } \\
\text { - today: } \sim 20 \text { clients (engineering) }\end{array}$ \\
\hline
\end{tabular}

Table 3-2 - Mapped case studies 


\section{References}

[1] W. Liu, Y. Zeng, M. Maletz, and D. Brisson, "Product Lifecycle Management: A Survey," Proc. ASME 2009 Int. Des. Eng. Tech. Conf. Comput. Inf. Eng. Conf. (IDETC/CIE 2009), no. 2007, pp. 1213-1225, 2009.

[2] S. Terzi, A. Bouras, D. Dutta, M. Garetti, and D. Kiritsis, "Product lifecycle management - from its history to its new role," Int. J. Prod. Lifecycle Manag., vol. 4, no. 4, p. 360, 2010.

[3] F. Nyffenegger, L. Rivest, and C. Braesch, "Identifying PLM themes, trends and clusters through ten years of scientific publications," in International Conference on Product Lifecycle Management, 2016.

[4] S. Bhatt, F. H. Tseng, N. Maranzana, and F. Segonds, "Scientometric Study of Product Lifecycle Management International Conferences: A Decade Overview.," in International Conference on Product Lifecycle Management, 2010, pp. 1-8.

[5] M. Abramovici, "Future Trends in Product Lifecycle Management (PLM)," in The Future of Product Development, 2007, pp. 665-674.

[6] I. Madjar, "Cyclical Trends in PLM Is PLM Recycling Itself Over and Over?," LinkedIn, $2017 . \quad$ [Online]. Available: https://www.linkedin.com/pulse/cyclical-trends-plm-recycling-itself-overilan-madjar.

[7] Oleg Shilovitsky, "PLM Waves - The History of the future," blog Beyond $P L M, 2017$. [Online]. Available: https://beyondplm.com/2017/02/04/plmwaves-history.

[8] Oleg Shilovitsky, "How to Escape from old PLM Ideas," blog Beyond PLM, 2016. [Online]. Available: http://beyondplm.com/2016/11/14/escape-old-plmideas/.

[9] Oleg Shilovitsky, "How to Break Limits of exisiting PLM Architectures," blog Beyond PLM, 2015. [Online]. Available: http://beyondplm.com/2015/03/13/ how-break-limits-of-existing-plmarchitectures/.

[10] Jos Voskuil, "Best Practices or Next Practices?," Jos Voskuil's Weblog, 2016. [Online]. Available: https:/virtualdutchman.com/2016/09/25/best-practicesor-next-practices/.

[11] Gartner Inc., "What is Bimodal IT?," Gartner.Com, 2015. [Online]. Available: http://www.gartner.com/it-glossary/bimodal. [Accessed: 28-Feb2017].

[12] E. Commission, "What is an SME," Entrepreneurship and Small and medium-sized enterprises (SMEs), 2016. [Online]. Available: http://ec.europa.eu/ growth/smes/business-friendly-environment/smedefinition_de. 